\title{
EL GRONISTA INDIO GUAMAN POMA DE AYALA Y LA CONCIENCIA CULTURAL PLURALISTA EN EL PERÚ COLONIAL
}

De acuerdo con el programa de Tartu para el estudio semiótico de los sistemas secundarios de modelización, la diversidad estructural interna de la Nueva corónica y buen gobierno, escrita entre 1585 y 1615 por el indio peruano Felipe Guaman Poma de Ayala, puede ser discutida al nivel de su plurilingüismo ${ }^{1}$.

En primer lugar, se trata de un plurilingüismo efectivo: Guaman Poma cuyo nombre emblemático liga al halcón del mundo de arriba con el puma del mundo de abajo; tenía diez años cuando empezó la conquista, y era un quechuahablante de la provincia de Guamanga, miembro étnico de los lucanas; y, efectivamente, la lengua quechua es el primer modelo cultural, verdadera matriz formalizadora, cuya poderosa función categorizadora supone a la fuente cultural donde la información recibida, decodificada y procesada, gana su orden, su sentido y su función. Nos falta todavía estudiar con detalle las funciones semióticas de este modelo del mundo que se convierte en este libro en un modelo del discurso; porque Guaman Poma produce su Corónica de 1189 páginas y 450 dibujos como una cápsula del tiempo escrito: preserva toda la información posible sobre su mundo quechua para salvarlo de la destrucción de la conquista y la colonización espanolas, y de ese modo confía al discurso la memoria del porvenir².

1 "Program proposal of the fourth summer workshop on secondary modeling systems", Dispositio, 1 (1976), 216-218. Véanse también B. A. UsPenskiJ, V. V. Ivanov, V. N. Toporov, A. M. Pjatigorskij, y J. M. Lotman, "Theses on the semiotic study of cultures (as applied to Slavic texts)" en Jan Van der Eng y Mojmir Grygar (eds.), Structure of texts and semiotics of culture, Mouton, The Hague-Paris, 1973, y J. M. LotMan, "Problems in the tipology of culture", en Daniel P. Lucid (ed.), Soviet semiotics, The John Hopkins University Press, Baltimore, 1977, pp. 213-221.

${ }^{2}$ Felipe Guaman Poma de Ayala, El primer nueva corónica y buen gobierno, 
El quechua funciona en esta empresa cultural como sustrato del código español, ya que la lengua española es un acto de comunicación política: Guaman Poma se dirige al rey Felipe III para persuadirlo de reformar la empresa colonial y para aconsejarle sobre la suerte de las Indias; pero la fuente de su información, siendo, en buena parte, producto de crónicas, relaciones y repertorios de la evangelización, tiene como modelo el orden natural del mundo aborigen, cuya formalidad es el quechua. Guaman Poma revela estructuralmente el movimiento de la cultura peruana en formación, y es su primera inscripción tanto como su primera conciencia resolutiva, ya que no se limita a comprobar la diferencia de lo nuevo sino que persigue reordenarlo dentro de sus propios códigos. Esto es, desde la cultura aborigen, Guaman emprende un doble trabajo sígnico: incorporar la información occidental a las pautas culturales propias; y, en consecuencia, recodificar la existencia social y política andina de acuerdo con la nueva experiencia histórica.

No se puede, por ello, hablar de mestizaje en el caso de este texto y este autor, como sí cabría hacerlo en el caso de Garcilaso, porque la noción de mestizaje implica una cierta nivelación de información, según la cual signos aborígenes y españoles se suman e integran, en una nueva entidad sintética, armónica y suficiente. Pero lo cierto es que esa noción de mestizaje sólo existe en el discurso, tanto en el del Estado regidor de los modelos de la sociedad nacional que generalmente son modelos de la clase dominante, como en el discurso liberal, que mecánicamente adscribe la verdad a la conciliación de los extremos, y este conformismo acrítico es característico de la ideología del mestizaje. El hecho es que la observación etnológica y antropológica documenta un proceso no de aculturación (incorporación total a la otra cultura) ni de mestizaje (promovido por la ideología de la "integración" para absorber la identidad aborigen en la sociedad nacional), sino de un pluralismo cultural de distinto grado de sincretismo. Este sincretismo hace que la información básica aborigen incorpore conjuntos de información occidental de modo heteróclito, a veces dis-

eds. John V. Murra y Rolena Adorno, trad. y análisis textual del quechua de Jorge L. Urioste, Siglo XXI, México, 1980, 3 ts. Hay también una edición debida a Franklin Pease en la Biblioteca Ayacucho, Caracas, 1980, 2 ts. El manuscrito, depositado en la Biblioteca Real de Copenhague, fue descubierto en 1908 y publicado por primera vez en edición facsimilar por Paul Rivet en el Museo del Hombre, París, 1936 (en la colección Travaux et Mémoires de l'Institut d'ethnologie). 
funcional, de acuerdo con las propias pautas de decodificación ${ }^{3}$. Por ello, esta incorporación de datos está regida por la propia función sígnica nativa: el quechua, en el caso de Guaman Poma, será, incluso a nivel lingüístico, el espacio de conversiones, incorporaciones y reordenamientos. Tanto, que una verdadera transcodificación se produce: Guaman incorpora modelos discursivos, pautas retóricas, formalizaciones occidentales (como la didáctica evangelizadora, la genealogía, la hagiografía, etc.) pero lo hace disfuncionalmente, o en una función inusitada (incluso el prólogo, que ubica no al comienzo de sus capítulos sino al final, como recuentos apelativos al lector). En efecto, éste es otro de los usos plurales del discurso: el discurso es una suerte de máquina de la memoria (porque preserva los órdenes de la cultura nativa, la lógica de su sentido), pero también es un instrumento mediador que transforma el dato occidental en dato aborigen para, en seguida, presentar el dato aborigen en su propia racionalidad y dentro del nuevo orden del mundo cristiano-español. De ese modo, la cultura se preserva, desde el quechua, gracias a la lengua española: la cultura quechua se apodera de la española para responder a la violencia colonial, para ilustrar la bondad de su sabiduría, para persuadir de su defensa al poder imperial. También para darle un destino a los protagonistas del discurso y de la historia, como el propio Guaman, autor de sí mismo en el texto, y anticipado autor de su destino cultural en un mundo donde, habiéndolo perdido todo, le queda el discurso para preservar a los suyos.

Pero este plurilingüismo es efectivo porque además del quechua Guaman Poma utiliza otras lenguas nativas, como el aymara, y es importante discutir su relación con las mismas. La Corónica es, como sabemos, un gran archivo textual: Guaman utilizó todos los modelos discursivos que pudo conocer para reajustarlos a su propia necesidad expositiva, a su estrategia comunicativa cultural, de manera que la convención retórica de esos repertorios

${ }^{3} \mathrm{He}$ analizado estos temas en mi ensayo "Crisis, identidad y cultura en el Perú", en Perú: identidad nacional, GEDEP, Lima, 1979, y en mi monografía Texto, comunicación y cultura: "Los ríos profundos" de José María Arguedas, CEDEP, Lima, 1982; también publicado en la NRFH, 31 (1982), 44-82. Ya en sus cartas Colón habla de la "disformidad fermosa" de las palmas, que dice las "hay de seis o de ocho maneras, que es admiración verlas": esa "disformidad fermosa" debe ser el primer intento de exceder el oxímoron cultural de lo diferente y sin embargo hermoso; con lo cual, el almirante propone el primer sincretismo de la representación discursiva de Indias. 
adquiere en su crónica una operatividad semiótica decisoria; pero, además, la Corónica es un archivo de voces, un magnífico escenario oral, donde escuchamos la palabra remota de los grupos étnicos tanto como las voces urgidas de los sectores sociales en formación; en este sentido, hay una oralidad pre-textual, una actualidad espectacular de lo hablado, que proviene incluso de la actividad escritural porque Guaman Poma se presenta como el intérprete de las voces sin escritura, que le hablan y le informan para que él registre luego en su Corónica las noticias y las quejas. El libro es también un testimonio de primera mano, y aunque sea difícil reconstruir la enunciación misma de esos testimonios, que pasan por la mediación de la escritura, sí es evidente que la escritura opera como la recuperación de lo vivo desconocido, u ocultado, a través de la oralidad inmediata; así, la escritura se entrega a la acción de la denuncia, y lo hace al modo de un juicio en el que los testigos proveen la fuente de la verdad. Sin embargo, esas voces sin la escritura sólo revelan su desamparo histórico: la escritura es el instrumento más valioso del conquistador, y apoderarse de ella significa incorporar a la propia oralidad una dimensión persuasiva poderosa; lo escrito es el testimonio oral que no calla, el habla que no cesa, la herida abierta. Por eso Guaman dice que "escribir es llorar"; escribir es perpetuar al testigo en el dolor de su testimonio. No hay duda sobre el carácter oral de esta escritura, y no sólo por su naturaleza fonética: Guaman, en efecto, escribió el español no de acuerdo con las reglas prosódicas y ortográficas, aunque eran en su tiempo poco fijas, sino de acuerdo con la pronunciación: escribió un español hablado, pero, además, un español hablado por un indio, es decir, de acuerdo con la escritura fónica del quechua. Es así como convirtió las cinco vocales del español a las tres del quechua, de modo que reescribió el español desde el quechua. El lingüista Jorge Urioste, responsable de las traducciones del quechua en la edición crítica de la Nueva corónica y buen gobierno (1981) emprendió una tarea reveladora: la refonologización del quechua escrito por Guaman; esto es, transcribió las palabras escritas por Guaman como éste debió haberlas pronunciado, devolviendo así al quechua original esas palabras distorsionadas por el español. Urioste propone que el autor decía no Guaman Poma, que es lo que escribió, sino Waman Puma, que es lo que debió escribir si su manejo del español hubiese sido más desarrollado. De acuerdo con esta tesis, la escritura fonética de Guaman debe ser revisada a nombre del código quechua. Pero hay aquí dos problemas: el primero es que precisamente esa 
escritura revela la incorporación sincrética del español, y es en el mismo nivel sígnico donde vemos, como en un corte estructural, el programa mayor de la cultura en acción transcodificadora; el segundo problema es que habría, entonces, que hacer lo mismo con el español de Guaman: convertirlo a un idioma correcto y formalizado, lo cual sería, por cierto, una violencia homogeneizadora y una pérdida de la diferencia cultural que está marcada en la aparente incorrección de un español que nos suena al característico idiolecto del hablante reciente de la Sierra peruana, con su distorsión vocálica y transposición sintáctica.

El carácter oral del texto está marcado por la función testimonial del autor, como hemos visto. Pero, asimismo, por su función metalingüística, Guaman se presenta como un "lengua", dedicado al nuevo oficio de la traducción. La traducción tendrá en su Corónica una operatividad plural. Guaman explica que trabajó "cerviendo de lengua y conversando y preguntando", lo que hizo a las órdenes del extirpador de idolatrías Cristóbal de Albornoz. Más adelante, en el proceso formativo de su propia conciencia cultural sobre el país, que ocurre en el mismo proceso de la escritura, cuestionará su papel en esa práctica anticultural y antiaborigen: es la escritura de la obra lo que lleva a verificar el contrasentido de ese periodo de su vida. Pero Guaman, asimismo, ejecuta las funciones intermediarias del traductor al invertir su papel de ayudante de la extirpación: en uno de sus autorretratos se dibuja preguntando (en quechua y en aymara) a un grupo de indígenas, sólo que las respuestas ya no sirven al aparato religioso represor sino al texto cultural liberador. En este sentido cultural, el texto opera como un mecanismo de traducción de ida y vuelta: viene del mundo aborigen y va hacia el mundo español, para así persuadir al poder imperial de la necesidad de reformar la colonización para salvar a las Indias; pero a la vez, viene del mundo español (como sistema sígnico) y vuelve al mundo nativo como memoria, archivo y modelo; es decir, como programa regenerador que preserva sus funciones sustantivadoras en el seno mismo del imperio conquistador. El traductor ejecuta el traslado literal pero también el simbólico.

Notablemente, es la oralidad la dimensión decisoria: la escritura es su espejo hablado. Así se entiende que Guaman Poma utilice uno de los recursos más formalizados de la didáctica evangelizadora, el sistema de preguntas del neófito o nuevo cristiano y respuestas del sacerdote o conocedor de la doctrina, para figurar, en una verdadera anticipación mediadora cultural, un en- 
cuentro con el propio rey de España. El capítulo de las preguntas, al que acompaña un dibujo en el que Guaman se pinta de rodillas frente a Felipe III, respondiéndole puntualmente, invierte los roles: el Rey es ahora el neófito y Guaman el entendido. De este recurso formal se vale para ilustrar a la máxima autoridad terrestre sobre los males, errores y extravíos de la colonización, y recomendarle, en una suerte de sumario de la prolija argumentación del libro, remedios y medidas para reformar el gobierno de Indias y darle un mejor destino político dentro del imperio cristiano-español. De manera que Guaman oraliza aquí la escritura, dándole un papel eminentemente fónico, si bien éste sólo se entiende en un nuevo escenario cultural, en su ocurrencia disfuncional.

Las operaciones disfuncionales están en la práctica desconstructora que caracteriza a este texto como programa cultural: la oralidad es aquí una de las fuentes que desbasan, rebasan y reconducen el sentido político del discurso cultural; esto es, la posibilidad de que la cultura aborigen adquiera una autonomía relativa dentro de un ordenamiento de carácter plural. Porque sólo en el pluralismo puede ser posible la subsistencia aborigen: la diferencia cultural requiere una política "de buen gobierno", de tolerencia, diálogo y paz. Guaman Poma, así, sostiene el programa de cultura sobre la reforma política. Dicho de otro modo, luego de haber andinizado el mundo (al revés del Inca Garcilaso, que unlversalizó al incario), Guaman requiere asegurar el orden humanizador y civilizado de la política como una relación de derecho, justicia y paz entre los hombres. Lo que Guaman está planteando al Rey, en buena cuenta, es la vigencia del pacto colonial: reclama que la legitimidad de la conquista y la colonización se cumpla de acuerdo con la letra de lo escrito. Y esta demanda por el código de la ideología dominante, incumplido de acuerdo con todos los testimonios, es una poderosa crítica específica al sistema colonial, tanto como su recusación política desde la legitimidad superior de la cultura. Con el pluralismo de las culturas, las razas y los saberes, Guaman recusa, tácitamente, la intolerancia unidimensional de la cultura etnocéntrica y hegemónica, incapaz de reconocer la humanidad de la diferencia. No en vano buena parte de su crítica se centra en la explotación del trabajo, en su desnaturalización por la violencia.

De manera que la oralidad es la fuente no sólo lingüística de la verdad sino también la razón histórica de la denuncia. Es así como la suma de las lenguas es la suma del país hablado y reco- 
rrido: para escribir su libro, nos dice Guaman, "escogí la lengua e fracis castellana, aymara, colla, puquina, conde yunga, quichua, inga, uanca, chinchaysuyo, yauyo, andesuyo, condesuyo, collasuyo cañari, cayampi, quito". Es sobre el escenario de esa oralidad, sobre su práctica expansiva, incorporadora y transcodificadora, donde se construye esta Corónica más hablada que escrita: o escrita con el habla transitiva de una cultura que se moviliza poderosamente hacia la apropiación del instrumento que da una mejor voz a sus voces urgentes. El texto está impregnado de esta función oralizadora de los signos, como si la grafía fuese la instancia inquieta del registro, el sistema de inscripción más que de transcripción; porque así como el dibujo da cuenta didáctica de los hechos, los roles y las funciones, la grafía es una pre-escritura, un fono-texto que no se fija, que transcurre con la misma nerviosa actualidad de la voz amenazada de silencio. Luego de cumplir con todo el ritual de quien pide la palabra, Guaman se apodera de ella y ya no deja de hablar, y de hacer hablar. El habla le sirve incluso para burlarse de los nuevos grupos sociales, y la parodia de las normas revela su ironía; se mofa, por ejemplo, de los criollos registrando los diminutivos: "Nuestro hijito Yaguito que sea cleriguito y Francisquito también".

Pero Guaman no ignora el poder de la escritura. Más aún: la recomienda a los indios como un aprendizaje necesario para los nuevos tiempos, cosa que también recomendaba el Inca Garcilaso recordando la habilidad de sus condiscípulos. De sus discípulos habla Guaman, para protestar otra vez, porque la escritura en manos de los indios es un peligro que la autoridad colonial sanciona; y alguno de sus discípulos, como él mismo, ha sido castigado duramente por representar a los demás en lo escrito, por la función política de la escritura ${ }^{4}$. Ni siquiera los curas quieren tratar con los indios ladinos que saben leer y escribir, protesta Guaman. Por lo demás, Guaman debe haber confiado en el poder persuasivo de su propio texto, que llevó con sus manos al palacio del virrey en Lima, como una carta al Rey, a quien más tarde le reclamó noticias de su envío. Escribir se ha convertido en el propósito de su vida de viejo y sabio (declara ser viejo de ochenta años); ha recorrido el país, nos dice, por más de treinta años, preguntando y escribiendo, respondiendo con lo escrito al dolor acu-

${ }^{4}$ Cristóbal de León, su discípulo, explica Guaman, fue perseguido por el corregidor de Lucanas, quien lo apresó, lo castigó en el cepo, quemó su casa y lo desterró. Su pecado fue haber presentado quejas contra el corregidor. 
mulado. El texto se convierte, a sus ojos, en la última esperanza de la reforma: el libro posee la convicción de la verdad, y el Rey, al conocerla, ordenará el bueno gobierno. La carta lleva un proyecto político: la reforma del Universo según la cosmogonía cuatripartita indígena; cada parte bajo un príncipe, y el emperador español como el nuevo Inca de una cristiandad andina ${ }^{5}$.

Podemos, ahora, precisar las operaciones semióticas del plurilingüismo literal del texto como un poliglotismo cultural; en efecto, la lengua es la base remodeladora de las culturas, y no sólo porque las dice, inscribe y cataloga, sino porque las lenguas se cruzan allí donde las culturas se comunican, libres ya de la violencia y sin perder su identidad propia. Guaman, como intérprete del desorden, debe hablar todas las lenguas para proponer que coexistan todas las culturas. Por eso, cuando está minuciosamente describiendo la bondad de los roles sociales, las técnicas y el control económico del medio en el mundo incaico, está reafirmando el modelo cultural gracias al idioma español. Todo ocurre como si, en la dimensión de lo escrito, el mundo indígena ampliase sus poderes en la nueva lengua, gracias a ella. La cultura aborigen ha ganado un instrumento para su desarrollo, sólo que antes requiere que se cumplan las leyes, o sea, ganar la paz.

Así, el sujeto es aquí histórico: da cuenta de sus funciones a partir del cambio y el desorden y a nombre de la reforma y el orden. El discurso es modelador: suma los testimonios para persuadir y cataloga el pasado para sostener el porvenir; esto es, empieza en el origen (en la Biblia y el Incario) para diseñar el porvenir (el Imperio y las Nuevas Indias). El objeto es procesal: si su naturaleza es debatible, el autor aporta las pruebas de su bondad: el indio, "pobre de Jesucristo", ha sido puesto en peligro, duda y escrutinio: Guaman lo convierte en nuevo Cristo; pero también en el verdadero agente de la riqueza y el poder español (Castilla es Castilla por los indios, dice). Por lo tanto, si el sujeto responsable del discurso es un hablante legítimo (príncipe, autor, traductor), ese alegato posee la certeza de la demostración, y, en

${ }^{5}$ Rolena Adorno, "Las otras fuentes de Guaman Poma: sus lecturas castellanas", Histórica, Lima, 2 (1978), 137-158, explica la idea de la restitucioń, según la cual Guaman creía que los españoles deberían devolver todas las tierras que habían tomado a los aborígenes: Guaman se basa en argumentos expuestos por el dominico Jerónimo de Loayza, arzobispo de Lima, inspirado a su vez en Las Casas. La autora desarrolla estas relaciones en otro ensayo: "El arte de la persuasión: el padre Las Casas y fray Luis de Granada en la obra de Waman Puma de Ayala", Escritura, Caracas, 1979, núm. 8, 167-189. 
consecuencia el objeto recuperado y reconstruido (la suerte del hombre de las Indias) se adelanta en estas operaciones como el protagonista más genuino de los nuevos tiempos y nuevo orden. De esa manera, Guaman Poma convierte a su escritura en un verdadero teatro: la enunciación que dice el testimonio es aquí el enunciado que hace la historia; con lo cual los destinatarios son los mismos protagonistas, ya que ellos hacen el discurso del que están hechos. Una vez más, Guaman es el operador semiótico de las hablas ejecutadas: abre el espacio de los que se hablan para acordar, en el consenso, el sentido de lo colectivo ${ }^{6}$.

La semiosis se produce como una teatralización del testimonio: el sujeto trae la voz autorizada por su grupo étnico, por la versión verificada por el padre; en contra de la opinión generalizada que favorece a los incas, Guaman aporta la voz étnica, con lo cual remplaza al Estado imperial destruido por los españoles, y sugiere que hay una autoridad previa y mayor: la del grupo étnico, el cual así como se ajustó al imperio inca puede muy bien reajustarse al imperio cristiano; este testigo privilegiado por su origen, a la vez se documenta con lo visto y oído, con lo preguntado y registrado; trae, de su mano, las pruebas ocultadas por el mal gobierno y, con la denuncia, induce la reforma esperada. Este productor y testigo de su propio discurso convierte a su texto en un testimonio de doble código: el nativo, que subyace intacto, y el español, que provee la retórica suficiente para modelar la actualidad de lo atestiguado. Por fin, el destinatario se construye en el mismo acto de la emisión: reconoce su lugar en ella como enunciador de una parte específica del discurso; por lo tanto, tiene un papel en el.juicio oral y sumario que el autor ha construido como la estrategia comunicativa de su conciencia étnica y su inteligencia pluralista. La escritura permite esta semiosis reconstructora luego de la amplia desconstrucción del sistema colonial emprendida. Por ello, Guaman sabe que la escritura es un instrumento decisivo, y que el escritor o el escriba tiene una función social específica, no sólo mediadora sino también responsable. Ser responsable con su propio instrumento: este reclamo anuncia la conciencia de la letra en la conciencia de la cultura; dice Guaman: "el buen principal de la letra y lengua de español que sepa hacer una petición interrogatorio y vea el pleito. Que no sea bo-

${ }^{6}$ Rolena Adorno, a partir de Uspenskij, discute el punto de vista en la Corónica en su artículo "Of caciques, coyas, and kings: The intricacies of point of view", Dispositio, 4 (1979), 27-47. 
rracho y coquero ni jugador ni mentiroso en este reino'”.

Ahora bien, si el plurilingüismo sostiene al poliglotismo cultural, ello quiere decir que la oralidad testimonial requiere sostenerse sobre la articulación del hablante y el oyente, o del emisor y los destinatarios. Pronto, esas funciones del esquema de la comunicación se intercambian: en el gran testimonio de la historia presente vienen a declarar las víctimas y los victimarios, lo escrito y lo hablado, tanto la enciclopedia de Occidente como la enciclopedia andina. De ese modo, los productores del habla son los consumidores de la letra, espejo donde se reconocen como actores de su papel en la puesta en orden que el texto promueve. Así, el papel decisorio de los destinatarios, Guaman lo sabe, debe ser formulado de antemano, para que la carta al Rey no espere respuestas sino que las contenga todas por adelantado. Por lo mismo, para hablar a la pluralidad de las partes implicadas, Guaman Poma debe ser, él mismo, varios hablantes: el acto de emisión sólo puede ser plural.

A este nivel pragmático, el programa cultural es una acción sistemática. En primer término, Guaman Poma de Ayala se presenta como "príncipe": su autoridad de ex cacique, heredero del liderazgo de los señores de Lucanas, altos funcionarios en el imperio incaico, le confiere, por casta, la responsabilidad de responder a la crisis desestructurante. Esa función emisora se materializa en la "carta", que supone al destinatario máximo, el rey Felipe III, ya que en esta vinculación de corresponsales la autoridad legítima permite confianza en la verdad, consejo en el remedio, prudencia en el juicio: la carta mediadora se convierte en el proyecto de la reforma política: para imponer la ley cristiana y el buen gobierno es necesario detener la matanza, devolver los españoles a España, los moros a su patria, los negros a Guinea, y dejar solos a los indios en Indias: cada reino estará gobernado por un príncipe (Guaman recomienda a su hijo para rey del Perú), y el monarca español estará al centro, como emperador. Guaman ha sido acusado de racista por esta opinión, pero más serio es ver en ella su voluntad extrema de defensa del indígena, que temió podría desaparecer. La defensa cultural pasa aquí por la reorganización política, sólo que ese nuevo mundo imperial se arma sobre el esquema aborigen de lo alto y lo bajo, y de las cuatro partes correspondientes.

En segundo término, este emisor se desdobla en "viajero", que recorre el país, aunque en verdad recorrió sólo la región central del Perú, recogiendo información “'a ojos vista”, es decir, co- 
mo el testigo directo del testimonio incontestable. El discurso que produce es un "informe", dirigido a un destinatario decisivo, el de las "autoridades", para quienes comunica la dimensión urgente de la "denuncia". Todo el dramatismo de la actualidad, y la feroz recusación anticolonial, se da en esta dimensión del sistema comunicativo de la obra.

En tercer término, habla el "historiador", y éste es un emisor bastante enterado, que cita, por lo menos, a autores como José de Acosta, fray Martín de Murúa, Cabello de Balboa, Agustín de Zárate, Diego Fernández de Palencia ("tienen muchos errores", dice), Fernández de Oviedo, aparte de fray Luis de Granada, diccionarios y legislación colonial. Este historiador cumple una función crítica, y es el autor de una "corónica", que se plantea como "nueva" por la validez y amplitud de las noticias verídicas que trae; se dirige, por lo mismo, a un "público culto", a una comunidad autorizada para apreciar su trabajo, del que se ufana, y su devoción a los hechos, que reclama. Así, el discurso se presenta como "verdad" documentada y comprobada.

En cuarto término, Guaman Poma habla como "sabio", como experto en lenguas y culturas aborígenes, capaz de haber asimilado la cultura española y la religión católica, su doctrina y verdad universal, con las cuales acuerda la racionalidad superior de su acto comunicativo, ya que el emisor comparte la plenitud de la ideología del destinatario, gracias a la cual ambos son verdaderos y legítimos en el discurso que los coinforma. Pero este sabio nativo se expresa a través de una "enciclopedia" alterna, desde la que reordena los capítulos de la realidad occidental; y aquí su destinatario son los "grupos étnicos", a los que el discurso representa en un ' modelo aborigen", en un programa que reanima; de allí que Guaman recomiende la escritura, a pesar de sus penurias.

En quinto término, el emisor de este discurso pluralizado se presenta también como "dibujante", a través de unos "dibujos" donde se ilustra, sin duplicación ni sustitución, el discurso descriptivo. Esta memoria iconográfica debe estar destinada a los analfabetos aborígenes, como un libro de ejemplos, ya que proviene del modelo de la hagiografía, y las vidas de santos eran el texto primario de la evangelización. Vemos, de este modo, que el dibujante ha cruzado, otra vez, los repertorios, al incorporar la técnica occidental a la perspectiva andina, ya que la estructuración de las figuras obedece, como ha visto muy bien Rolena Adorno, a las jerarquizaciones características de la representación andina, 
según las cuales la derecha y la izquierda, lo alto y lo bajo, y el centro mediador, suplen el orden estable de los roles y significados; por su parte, Mercedes López-Baralt ha visto cómo esta iconografía funciona de acuerdo con el "arte de la memoria", como un verdadero archivo cultural ${ }^{7}$.

En sexto lugar, el emisor se presenta como "traductor", según hemos visto, y esta función suya se materializa en los textos de otras lenguas, que traduce casi siempre, y en su discusión sobre el tema. Su destinatario parece ser el monolingüe, el español, a quien transmite un saber plural que busca preservar, de paso, en el texto. El discurso subraya su carácter plural, su destino políglota.

Por último, Guaman Poma gusta llamarse el "autor", y su conciencia de tal es muy aguda y operativa: sabe que no es letrado, que no habla latín, que no es culto, ni tiene la autoridad de los autores españoles; pero sabe también que es el otro autor, aquel que comienza con su función cultural determinante: la de preservar, dar cuenta, denunciar y demandar. Como autor, se expresa a través de una amplia biografía cultural, que se materializa en la obra en marcha, en proceso siempre, hecha de capítulos sucesivos y paralelos, ordenados de acuerdo con una necesidad clasificatoria demostrativa, didáctica por una parte y preservadora por otra. Se dirige a un destinatario no presente: a un "lector virtual"', que, como en el caso del Inca Garcilaso, configuraría el nuevo país, un país habitado por lectores que sean autores; por destinatarios que toman y hacen la nueva palabra histórica y cultural. A esa virtualidad, sin la cual, como dice Lévi-Strauss, no se entienden las sociedades, se dirige Guaman construyendo la "'memoria ejemplar", donde reconocerse en la identidad común gracias a la letra capaz de humanizar el mundo con los derechos de la pluralidad cultural.

Este sujeto hecho de la dignidad de su cultura y de la indignación de su testimonio crítico reconoce en su propia diversificación la estructura de la semiosis cultural pluralista. En los inicios de la formación de la conciencia pluriétnica de la cultura hispanoamericana, este sistema de comunicación producido por unáinte-

7 Mercedes López-Baralt, en su trabajo "Guaman Poma de Ayala, el arte de la memoria en una crónica ilustrada del siglo xvII", CuA, 1979, núm. 3, 119-147, discute las relaciones de los dibujos con la iconografía europea y la tradición pictórica incaica. Véase también Rolena ADORNo, "Paradigms lost: A Peruvian indian surveys Spanish colonial society", Studies in the Anthropology of Visual Communication, 1979, núm. 2, 78-96. 
lectual indígena, uno de los pocos que sobrevivieron a las varias colonizaciones depredadoras, se nos aparece como un verdadero programa cultural, donde, como dice Uspenskij, el proceso histórico es concebido como un proceso comunicativo ${ }^{8}$. Para darle sentido, para producir el sentido desde la cultura propia, Guaman Poma convirtió su experiencia histórica en un sistema textual complejo. Dio cita a todos los protagonistas de su tiempo en un texto anticolonialista cuya inquietante actualidad nos incluye: todavía sus preguntas son las nuestras ${ }^{9}$.

Julio Ortega

University of California, Santa Barbara

${ }^{8}$ B. A. UsPenskiJ, "Historia sub specie semioticae", en Daniel P. LuCID (ed.), op. cit., pp. 107-115.

${ }^{9} \mathrm{He}$ analizado otros problemas planteados por la escritura y el texto de la Corónica, en su dimensión semiótica cultural, en mis ensayos "La Corónica de Guaman Poma: historia y ficción", en Socialismo y participación, Lima, 1980, núm. 10, y "Guaman Poma de Ayala y la producción del texto", $\mathrm{CuH}, 360$ (1980), 600-611. 